\title{
Does Access Location Influence Outcome of Percutaneous Nephrolithotomy in Staghorn Stones?
}

\author{
Serkan Yarimoglư ${ }^{1}$, Murat Sahan ${ }^{1}$, Salih Polat ${ }^{2}$, Gurkan Cesur ${ }^{1}$, Omer Koras ${ }^{3}$ and Tansu Degirmenci ${ }^{1}$ \\ ${ }^{1}$ Department of Urology, HSU Izmir Bozyaka Training and Research Hospital, Izmir, Turkey \\ ${ }^{2}$ Department of Urology, Faculty of Medicine, Amasya Unisersity, Amasya, Turkey \\ ${ }^{3}$ Department of Urology, Faculty of Medicine, Hatay University, Hatay, Turkey
}

\begin{abstract}
Objective: To assess the effect of lower and middle calyceal accesses on the outcomes of percutaneous nephrolithotomy (PCNL) in staghorn stones.

Study Design: Observational study.

Place and Duration of Study: Department of Urology, University of Health Sciences, Izmir Bozyaka Training and Research Hospital, Turkey, from April 2012 to January 2019.

Methodology: Patients who underwent PCNL for staghorn stones were retrospectively analysed. The patients were grouped as Group-1 (middle calyceal access) and Group-2 (lower calyceal access). Demographic and stone characteristics (size, density), perioperative and postoperative data, and stone-free rates were compared between these two groups. Postoperative detection of $>4 \mathrm{~mm}$ stones was defined as residual stones.

Results: There were 249 patients in the study; 108 in middle calyceal access group and 141 in lower calyceal access group. The mean stone burden was 765 (524-1322) and 777 (490-1445) $\mathrm{mm}^{2}$ in group- 1 and group-2, respectively $(p=0.876)$. The number of stone-free patients was $50(46.3 \%)$ in middle calyceal access group and $93(66.0 \%)$ in lower calyceal access group. The rate of stone-free status was significantly higher in lower calyceal access group $(p=0.002)$. The overall complication rate was similar between the groups $(p=0.132)$. The binary analysis showed that stone burden, and calyx of entry were predictive factors for success.

Conclusion: Although the choice of the calyx to be entered does not affect the complication rate in staghorn stones, the stonefree rate is significantly higher in lower calyceal access.
\end{abstract}

Key Words: Percutaneous nephrolithotomy, Staghorn stones, Clavien scoring system, Calyx, Access.

How to cite this article: Yarimoglu S, Sahan M, Polat S, Cesur G, Koras O, Degirmenci T. Does Access Location Influence Outcome of Percutaneous Nephrolithotomy in Staghorn Stones?. J Coll Physicians Surg Pak 2021; 31(09):1075-1080.

\section{INTRODUCTION}

Staghorn stones are branched and usually infected stones that occupy a large part of the collecting system. ${ }^{1}$ Failure to remove staghorn stones may result in the destruction of the renal parenchyma, leading to the complete loss of kidney function and development of sepsis. Guidelines recommend percutaneous nephrolithotomy (PCNL) as the gold standard treatment for kidney stones greater than $2 \mathrm{~cm} .{ }^{2}$ The overall success in patients undergoing PCNL has been reported to reach $96.1 \% .^{3}$

Correspondence to: Dr. Murat Sahan, Department of Urology, HSU Izmir Bozyaka Training and Research Hospital, Izmir, Turkey

E-mail: muratsahan87@hotmail.com

Received: June 11, 2021; Revised: July 29, 2021;

Accepted: August 26, 2021

DOI: https://doi.org/10.29271/jcpsp.2021.09.1075
However, since more than one percutaneous access may be required to extract all stone pieces in staghorn stones, it is very difficult to reach stone-free status in a single access in these patients. ${ }^{4}$ A previous study reported that the stone-free rate in staghorn stones was decreased to $56.9 \% .{ }^{5}$ In addition to these low stone-free rates after PCNL, staghorn stones also have high complication rates. In a prospective randomized study, theintraoperative complication rate of PCNL applied in the treatment of staghorn stones was found to be $16.3 \%$, and the major postoperative complication rate was determined as $18.6 \%{ }^{6}$

The access site in PCNL depends on various factors, such as surgeon preference, renal anatomy, stone location, and total stone burden. In studies, generally accepted view is that calyces other than the lower calyx allow for easier dilatation through the placement of the guide into the ureter from the ureteropelvic junction, resulting in less manipulative trauma and providing a higher stone-free rate. However, the possibility of intercostal access increases in upper calyceal access, which increases the possibility of bleeding due to thoracic complications, including pneumothorax and hydrothorax. ${ }^{7-10}$ On the 
other hand, in lower calyceal access, there is a higher risk of colonic injury. ${ }^{11}$ As stated by Miller etal., access site should facilitate the use of rigid instruments, increase the stone-free rate, and reduce the complication rate to the lowest levels. ${ }^{12}$

The aim of this study was to compare the outcomes of lower and middle calyceal accesses in single-access PCNL performed in a challenging patient group, i.e. staghorn stones.

\section{METHODOLOGY}

This study was a retrospective analysis of patients who underwent PCNL for staghorn stones at the Izmir Bozyaka Training and Research Hospital from April 2012 to January 2019. The study was approved by the Hospital Ethical Board (Meeting/Decision No.2021/71). All the data of the patients were obtained from electronic medical records.

Patients with congenital kidney anomalies, coagulopathy, skeletal deformity, and solitary kidney, those without staghorn stones, and cases in which multiple accesses used, were excluded from the study. The patients were grouped as lower and middle calyx access: Group-1 (middle calyceal access) and Group-2 (lower calyceal access). Demographic and perioperative data were compared between these two groups.

All patients were evaluated preoperatively using standard non-contrast abdominal computed tomography (CT). The patients' data were recorded by the surgeon. Preoperatively, all patients signed an informed consent form; and were evaluated in terms of stone-free status and complication. Stone-free status was accepted as the presence of stones $<4 \mathrm{~mm}$ or no stone detected on follow-up. CT undertaken in the first month after surgery. Postoperative complications were analysed according to the Clavien scoring system. ${ }^{13}$

Stone burden was calculated in square millimeters in all patients as follows: width $x$ length $\times \pi \times 1 / 4$, where $\pi$ was taken as $3.14 .^{14}$ For staghorn stones, this calculation was performed separately for each calyceal location, and the sum of all calculations were accepted as results. All the PCNL operations were performed by experienced urologists.

The operation began with the insertion of a 5 or $6 \mathrm{~F}$ ureteric catheter into the renal pelvis in the lithotomy position under general anesthesia. Subsequently, the kidney was accessed from the lower or middle calyx group with an 18-gauge needle in the prone position under fluoroscopy, depending on the location of the stone and the anatomy of the kidney. The site of entry was dilated up to 30 Fr with Amplatz dilators, and a rigid nephroscope was used to enter the pelvicalyceal system. The stones were fragmented using a pneumatic lithotriptor (Elmed; Vibrolith;Ankara/Turkey). Single-access PCNL was performed in all patients. A14 F nephrostomy catheter was placed postoperative in all patients, and antegrade pyelography was performed.

Categorical data were given as numbers and percentages of columns. The Shapiro-Wilk test was used to examine the conformity of the continuous variables to the parametric distribution. Continuous data were presented as mean value and standard deviation (SD); and median value and inter-quartile range according to whether they fit the normal distribution or not. In the comparison of countinuous data, either Mann-Whitney Utest or Independent-samples t-test was used as appropriate. Pearson's Chi-square and Fisher's Exact tests were used for inter-group comparison of categorical variables. Univariate and multivariate binary logistic regression analyses were performed to analyse possible predictive factors associated with stone-free status. A p-value of $<0.05$ was considered statistically significant. SPSS software (version 23.0; IBM Corporation, Armonk, NY, USA) was used for the statistical analyses.

\section{RESULTS}

There were 249 patients in the study, 108 were in middle calyceal access group and 141 were in lower calyceal access group. The median age of the patients was 49 (37-60) and 50 (38-57.5) years in Group-1 and Group-2, respectively $(p=0.856)$. The number of patients with comorbidities was similar in both groups $(p=0.267)$. Stone burden and density were also similar in both the groups $(p=0.876$ and $p=0.352$, respectively, Tablel).

Table I: Patients'characteristics between the groups.

\begin{tabular}{|c|c|c|c|}
\hline & Group 1 (n:108) & Group 2 (n:141) & p-value \\
\hline Age, (years) & $49(37-60)$ & $50(38-57.5)$ & 0.856 \\
\hline $\begin{array}{l}\text { Gender; male/female, } \\
n / n\end{array}$ & $69 / 39$ & $99 / 42$ & $0.291 *$ \\
\hline $\mathrm{BMI}, \mathrm{kg} / \mathrm{m}^{2}$ & $\begin{array}{c}26.1 \\
(22.6-29.4)\end{array}$ & $27.4(23.6-30.4)$ & 0.117 \\
\hline $\begin{array}{l}\text { Metabolic Syndrome, } \\
\mathrm{n}(\%) \\
\text {-Absent } \\
\text {-Present }\end{array}$ & $\begin{array}{c}103(95.4) \\
5(4.6)\end{array}$ & $\begin{array}{c}133(94.3) \\
8(5.7)\end{array}$ & $0.714^{*}$ \\
\hline $\begin{array}{l}\text { Comorbidity } \\
\text {-Diabetes mellitus } \\
\text {-Hypertension } \\
\text {-Coronary artery } \\
\text { disease } \\
-\geq 2\end{array}$ & $\begin{array}{l}4(3.7) \\
7(6.5) \\
9(8.3) \\
4(3.7)\end{array}$ & $\begin{array}{l}15(10.6) \\
12(8.5) \\
13(9.2) \\
6(4.3)\end{array}$ & $0.267 *$ \\
\hline Side; left/right, n/n & $55 / 53$ & $80 / 61$ & $0.362 *$ \\
\hline Stone burden, $\mathrm{mm}^{2}$ & 765 (524-1322) & 777 (490-1445) & 0.876 \\
\hline Stone density, HU & $\begin{array}{c}1120 \\
(900-1200)\end{array}$ & $\begin{array}{c}1100 \\
(800-1300)\end{array}$ & 0.352 \\
\hline $\begin{array}{l}\text { Parenchymal } \\
\text { thickness, } \mathrm{mm}\end{array}$ & $13.6 \pm 4.5$ & $15.0 \pm 4.6$ & 0.060 \\
\hline $\begin{array}{l}\text { Previous Ipsilateral } \\
\text { Surgery, } \mathrm{n}(\%) \\
\text {-Absent } \\
\text {-Present }\end{array}$ & $\begin{array}{l}68(63.0) \\
40(37.0)\end{array}$ & $\begin{array}{c}103(73.0) \\
38(27.0)\end{array}$ & $0.089 *$ \\
\hline Preoperative $\mathrm{Hgb}, \mathrm{g} / \mathrm{dL}$ & $13.9 \pm 1.8$ & $13.9 \pm 1.7$ & 0.345 \\
\hline $\begin{array}{l}\text { Preoperative GFR, } \\
\mathrm{ml} / \mathrm{min}\end{array}$ & $90.2 \pm 30.0$ & $90.9 \pm 29.7$ & 0.868 \\
\hline
\end{tabular}

Regarding the perioperativeand postoperative outcomes, operative, nephroscopy and fluoroscopy times, and hospitalisation time were similar in both the groups $(p=0.343, p=0.330$, $p=0.884$, and $p=0.055$, respectively). The number of cases in which intercostal access was used was significantly higher in middle calyceal access group $(p<0.001)$. The median droping hemoglobin was $1.65(0.80-2.60) \mathrm{g} / \mathrm{dL}$ in Group-1 and 1.90 
(1.05-2.70) $\mathrm{g} / \mathrm{dL}$ in Group-2 ( $p=0.322)$. The number of patients requiring transfusion replacement was similar in both the groups $(p=0.346$, Table II).

Table II: Perioperative ve postoperative outcomes.

\begin{tabular}{|c|c|c|c|}
\hline & $\begin{array}{l}\text { Group 1 } \\
(\mathrm{n}: 108)\end{array}$ & $\begin{array}{l}\text { Group } 2 \\
(n: 141)\end{array}$ & p-value \\
\hline $\begin{array}{l}\text { Access level, } \mathrm{n}(\%) \\
-11^{\text {th }}-12^{\text {th }} \text { intercostal } \\
\text {-Subcostal }\end{array}$ & $\begin{array}{l}62(57.4) \\
46(42.6)\end{array}$ & $\begin{array}{l}29(20.6) \\
112(79.4)\end{array}$ & $<0.001^{*}$ \\
\hline Operative time, (min) & $120(90-150)$ & $120(90-145)$ & 0.343 \\
\hline Nephroscopy time, (min) & $50(40-90)$ & $50(40-70)$ & 0.330 \\
\hline Fluoroscopy time, (sec) & $65(45-92)$ & $68(40-98.5)$ & 0.884 \\
\hline $\begin{array}{l}\text { Hospitalization time, } \\
\text { (day) }\end{array}$ & $4(3-5)$ & $3(2-4.5)$ & 0.055 \\
\hline Hgb drop, (g/dL) & $\begin{array}{c}1.65 \\
(0.80-2.60)\end{array}$ & $\begin{array}{c}1.90 \\
(1.05-2.70)\end{array}$ & 0.322 \\
\hline GFR change, $\mathrm{ml} / \mathrm{min}$ & $\begin{array}{c}-11.0(-18.0 \text { to } \\
-2.41)\end{array}$ & $\begin{array}{c}-9.4(-17.2 \text { to } \\
0)\end{array}$ & 0.278 \\
\hline Transfusion rates, $\mathrm{n}(\%)$ & $14(13.0)$ & $13(9.2)$ & $0.346 *$ \\
\hline Stone free rates, $\mathrm{n}(\%)$ & $50(46.3)$ & $93(66.0)$ & $0.002 *$ \\
\hline $\begin{array}{l}\text { Clavien-Dindo } \\
\text { classification, n(\%) } \\
\text {-No complication } \\
\text {-Clavien I-II } \\
\text {-Clavien III-V }\end{array}$ & $\begin{array}{l}66(61.1) \\
27(25.0) \\
15(13.9)\end{array}$ & $\begin{array}{c}99(70.2) \\
31(22.0) \\
11(7.8)\end{array}$ & $0.205^{*}$ \\
\hline
\end{tabular}

Table III: Classification of complications according to Clavien scoring system.

\begin{tabular}{|l|c|c|c|}
\hline Complications & Group 1 (n:42) & Group 2 (n:42) & p value \\
\hline Grade I, $\mathrm{n}(\%)$ & $3(7.1)$ & $9(26.2)$ & $0.061^{*}$ \\
\hline -Pain & - & 4 & \\
\hline -Fever & 1 & 5 & \\
\hline $\begin{array}{l}\text {-Bleeding not requiring blood } \\
\text { transfusion }\end{array}$ & 2 & & \\
\hline Grade II, $\mathrm{n}(\%)$ & $24(57.1)$ & $22(47.6)$ & $0.661^{*}$ \\
\hline -Bleeding requiring blood transfusion & 9 & 13 & \\
\hline $\begin{array}{l}\text {-Postoperative fever }\left(>38^{\circ} \mathrm{C}\right) \text { managed } \\
\text { with antibiotics in the ward }\end{array}$ & 15 & 9 & \\
\hline Grade III & $14(33.3)$ & $11(26.2)$ & $0.474^{*}$ \\
\hline Grade III A, $\mathrm{n}(\%)$ & & & \\
\hline $\begin{array}{l}\text {-Urine leakage managed by ureteric } \\
\text { stenting without general anesthesia }\end{array}$ & 7 & 7 & \\
\hline $\begin{array}{l}\text {-Perinephric abscess managed by } \\
\text { percutanous drainage }\end{array}$ & 2 & 1 & \\
\hline -Hydrothorax & 2 & - & \\
\hline $\begin{array}{l}\text {-Renal hemorrhage requiring } \\
\text { angioembolization }\end{array}$ & - & 1 & \\
\hline Grade III B, $\mathrm{n}(\%)$ & 3 & 2 & \\
\hline $\begin{array}{l}\text {-Urine leakage managed by ureteric } \\
\text { stenting with general anesthesia }\end{array}$ & $1(2.4)$ & 0 & $0.999^{\wedge}$ \\
\hline Grade IV & & & \\
\hline Grade IV B, $\mathrm{n}(\%)$ & 1 & - & \\
\hline -Sepsis & & & \\
\hline * Pearson Chi-square; ^ Fisher's Exact Test. & & & \\
\hline
\end{tabular}

Stone-free status was detected in $50(46.3 \%)$ patients in lower calyceal access group and $93(66.0 \%)$ patients in middle calyceal access group $(p=0.002)$. Patients who had clinically significant residual stones after single-access PCNL, $w$ ere undergone extracorporeal shock wave lithotripsy (19 patients), retrograde intrarenal surgery (32 patients), and second lookPCNL (8 patients). Concerning the overall complication rates, complications were detected in 42 (38.9\%) patients in Group-1 and 42 (29.8\%) patients in Group-2 ( $p=0.132$, Table II).
When the authors examined complication subgroups formed according to the Clavien scoring system, they observed that the two groups had a similar distribution of complication grades (Table III).

In the univariate analysis, stone density (OR: $0.999, p=0.025$ ), stone burden (OR: $1.000 p=0.038$ ), and lower calyceal access (OR: 2.247, $p=0.002$ ) were found to be associated with stonefree status. The multivariate analysis conducted with stone burden (OR: $1.000 p=0.045)$, and lower calyceal access (OR: $2.289 p=0.002$ ) were independent risk factors for success.

\section{DISCUSSION}

Despite advances in instrumentation and technology, staghorn stones are still difficult to manage. PCNL is a preferred treatment method with a high success and low major complication rate in the treatment of complex kidney stones. ${ }^{15}$ However, there were some studies which showed that the success rate in staghorn kidney stones was decreased to $56.9 \%{ }^{5}$ Although some authors suggest the superiority of access through certain calyces for routine PCNL, there is an ongoing debate concerning which renal calyceal access achieves higher success in staghorn stones. In a retrospective evaluation of 153 PCNL procedures with ultrasound-guided access, the authors reported that the middle calyceal access had a shorter operative time (41 minutes) and higher stone-free rate (98\%) compared to the lower (50 min and $84 \%$, respectively) and upper (46 min and 93\%, respectively) calyceal access groups, but they observed no significant difference between the groups in relation to complications. ${ }^{16}$ In the CROES PCNL Global study, upper and lower pole accesses were compared in 4,494 patients that underwent single-access PCNL, and it was observed that the upper pole access group had a extended operative time and lower stone-free rate (77 versus $82 \%$ ), higher overall complication rate ( 23.5 versus $16 \%)$, and longer hospital stay. ${ }^{17}$ To the best of authors' knowledge, this study was the first study to assess the effect of middle and lower calyceal accesses on the outcomes of staghorn kidney stone treatment.

In this study, which aimed to compare the safety and efficiency of middle and lower pole accesses, only those cases were evaluated in which the surgeon considered only single access was required; and excluded those involving multiple entries. In a study by Verma et al. conducted with 110 PCNL cases with single and multiple accesses, it was observed that patients who required only one access site for stone removal had a larger infundibular area, greater intercalyceal angle, and smaller pelvicalyceal surface area. ${ }^{18}$ Although these parameters were not clearly measured in this study, such evaluation was made by retrograde pyelography performed in each case. When evaluating the access site in PCNL, it is important to know that kidney anatomy may differ between patients.

Although previous studies have reported higher stone-free rates (78-93\%) after PCNL in staghorn kidney stones, ${ }^{4,19}$ in the current study including staghorn stones, the success rate was 
$66.0 \%$ in the lower calyceal access group and $46.3 \%$ in the middle calyceal access group $(p=0.002)$. This lower rate of success can be explained by the exclusion of use of a single access in each patient, lithotripsy being performed with only a pneumatic lithotripter, and technical limitations caused by not using a flexible nephroscope. Previous studies have shown that middle calyceal access facilitates entry into many points of the pelvicalyceal system by providing greater maneuverability and is more advantageous than lower calyceal access, especially in staghorn and complex stones. ${ }^{16}$ In contrast, Blum et al. found the stone-free rate to be $77.3 \%$ in patients with a single lower calyceal access in staghorn kidney stones, while they found a stone-free rate of $68.2 \%$ in the single upper calyceal access group. ${ }^{20}$ Similarly, in this study, the stone-free rate was significantly higher in the lower calyceal access group. Choosing an appropriate access site is an important factor influencing success, but it is not possible to define it precisely since there are many other factors affecting success, such as different renal anatomy, stone size, density and type, and technical equipment used (flexible nephroscope, etc.). In present study, the authors found that stone burden, and lower calyceal access were independent risk factors for success. In a series of 498 patients, Binbay et al. examined the anatomical variations of the kidney and reported a positive correlation between a lower pelvicalyceal surface area and stone configuration and a high stone-free rate. ${ }^{21}$

In this study, in which only staghorn stones were included, there was no significant difference in the stone size of the two groups, which also shows the comparability of the groups in term of stone burden. In the present study, length of hospital stay, operative, fluoroscopy nephroscopy time, hemoglobin drop, and blood transfusion rate were found to be similar in both the groups. The access site being the lower or middle calyx has no effect on these parameters in complex stones. However, Caglayan etal. reported that factors such as renal parenchymal damage, forced tract dilatation, sharp renal axis angle, and increased torque due to limited manipulation in the lower calyceal access group might be associated with greater blood loss, increased number of residual stones, and longer operative time. ${ }^{22}$ In another study, it was shown that the renal pelvis and upper calyx could be accessed more easily using the posterior lower calyceal route and less torque would result in less damage to the renal parenchyma and infundibulum. It was also shown that the more medial approach can facilitate laterally located anterior lower calyceal access, and the use of a proper access angle into the infundibulum could provide better access to the rest of the collector system, including the interpolar calyces. In addition, an access angle that is less perpendicular to the collector system was suggested to facilitate the gravitational passage of materials through the sheath. ${ }^{21}$ Karve et al. reported that hemoglobin drop was $0.67 \mathrm{~g} / \mathrm{dL}$ in patients with a middle calyceal access and $1.36 \mathrm{~g} / \mathrm{dL}$ in those with a lower calyceal access $(p<0.001)$. The authors reported that transfusion rates were similar in both groups ${ }^{23}$. Similarly, in another study, while hemoglobin drop was significantly higher in the lower calyceal access group, there was no statistically significant difference intransfusion rates of the groups. ${ }^{16}$

The goal of upper urinary tract stone treatment methods is to provide maximum stone-free rates with minimum morbidity. PCNL is considered as an effective and safe treatment option for large kidney stones. Despite the proven efficacy of the PCNL, complication rates reaching $83 \%$ have been reported in the literature, including bleeding requiring transfusion (7\%), organ damage (0.4\%), and infectious events (up to $33 \%) .{ }^{24}$ In this study, the two groups had similar rates of major (13.9\% in Group- 1 and $7.8 \%$ in Group-2) and minor (25.0 and $22.0 \%$, respectively) complications. The overall complication rate was $38.9 \%$ in middle calyceal access group and $29.8 \%$ in lower calyceal access group; and there was no statistically significant difference between them. When the complication subgroups were examined according to the Clavien scoring system, it was seen that postoperative fever requiring antibiotics was more common than the other complications. This may be related to staghorn stones, generally being infected stones, and the presence of residual stones causing infectious events. Choosing an appropriate access site during PCNL plays a critical role in the success of the operation. Upper calyceal access provides direct entry into all renal calyces and the pelvis; however, the increased possibility of thoracic complications remains a major concern for urologists. Soares et al. showed that supracostal upper calyceal access was associated with a higher rate of thoracic complications. ${ }^{25}$ In this study, it was observed that hydrothorax developed in two cases in which supracostal middle calyceal access had been used. In light of this information, lower calyx of entry during the PCNL procedure should be preferred in staghorn kidney stones due to high success and similar complication rates.

There are some limitations to the generalisation of this study. First, it had a retrospective design and a limited number of patients. Second, there was no long-term results of surgical complications. Finally, there is a need for prospective studies with a larger series of patients with staghorn stones, focusing on the access site.

\section{CONCLUSION}

This study showed that, in PCNL applied to staghorn kidney stones using a single access, lower calyceal access was superior to middle calyceal access in relation to the stone-free rates. The selection of an appropriate access site in the treatment of staghorn kidney stones may vary according to patient factors and surgeon experience. The results of this study should be confirmed by further studies evaluating the efficacy of different calyceal access sites in staghorn kidney stones.

\section{ETHICALAPPROVAL:}

This study follows the principles of the Declaration of Helsinki; and it was approved by the Ethics Committee of the Turkish Ministry of Health, Izmir Bozyaka Training and Research Hospital (Meeting/Decision No. 2021/71). 


\section{PATIENTS' CONSENT:}

Informed consent was not obtained due to the retrospective nature of the study design.

\section{CONFLICT OF INTEREST:}

The authors declared no conflict of interest.

\section{AUTHORS'CONTRIBUTION:}

SY: Study conception and design, analysis and interpretation of data, wrote the paper.

MS: Study conception and design, wrote the paper.

SP: Acquisition of data, analysis and interpretation of data.

OK: Acquisition of data, critical revision.

GC: Analysis and interpretation of data, statistical analysis.

TD: Analysis and interpretation of data, critical revision.

\section{REFERENCES}

1. Ganpule AP, Desai M. Management of the staghorn calculus: Multiple-tract versus single-tract percutaneous nephrolithotomy. Curr Opin Urol 2008; 18(2):220-3. doi: 10.1097/MOU.0b013e3282f3e6e4.

2. Türk C, Petř́k A, Sarica K, Seitz C, Skolarikos A, Straub M, et al. eau guidelines on interventional treatment for urolithiasis. Eur Urol 2016; 69(3):475-82.

3. Wollin DA, Preminger GM. Percutaneous nephrolithotomy: Complications and how to deal with them. Urolithiasis 2018; 46(1):87-97. doi: 10.1007/s00240-017-1022-x.

4. Desai M, Jain P, Ganpule A, Sabnis R, Patel S, Shrivastav P. Developments in technique and technology: The effect on the results of percutaneous nephrolithotomy for staghorn calculi. BJU Int 2009; 104(4):542-8. doi: 10.1111/j.1464410X.2009.08472.x.

5. Desai M, De Lisa A, Turna B, Rioja J, Walfridsson $H$, D'Addessi A. The clinical research office of the endourological society percutaneous nephrolithotomy global study: Staghorn versus non staghorn stones. J Endourol 2011; 25(8):1263-8. doi: 10.1089/end.2011.0055.

6. Al-Kohlany KM, Shokeir AA, Mosbah A, Mohsen T, Shoma AM, Eraky l, et al. Treatment of complete staghorn stones: A prospective randomized comparison of open surgery versus percutaneous nephrolithotomy. J Urol 2005; 173(2):469-73. doi: 10.1097/01.ju.0000150519.49495.88.

7. Preminger GM, Assimos DG, Lingeman JE, Nakada SY, Pearle MS, Wolf JS Jr. AUA (nephrolithiasis guideline panel). Chapter 1: AUA guideline on management of staghorn calculi: diagnosis and treatment recommendations. J Urol 2005; 173(6):1991-2000. doi: 10.1097/01.ju.000016 1171.67806.2a.

8. Shah HN, Hegde SS, Shah JN, Bansal MB. Safety and efficacy of supracostal access in tubeless percutaneous nephrolithotomy. J Endourol 2006; 20(12):1016-21. doi: 10.1089/end.2006.20.1016.

9. Sukumar S, Nair B, Ginil KP, Sanjeevan KV, Sanjay BH. Supracostal access for percutaneous nephrolithotomy: Less morbid, more effective. Int Urol Nephrol 2008; 40(2):263-7. doi: 10.1007/s11255-007-9270-2.

10. Munver R, Delvecchio FC, Newman GE, Preminger GM. Critical analysis of supracostal access for percutaneous renal surgery. J Urol 2001; 166:1242-6.

11. Kyriazis I, Panagopoulos V, Kallidonis P, Özsoy M, Vasilas M, Liatsikos E. Complications in percutaneous nephrolithotomy. World J Urol 2015; 33:1069-77.

12. Miller NL, Matlaga BR, Lingeman JE. Techniques for fluoroscopic percutaneous Renal access. J Urol 2007; 178(1):15-23. doi: 10.1016/j.juro.2007.03.014.

13. Dindo D, Demartines $N$, Clavien PA. Classification of surgical complications: A new proposal with evaluation in a cohort of 6336 patients and results of a survey. Ann Surg 2004; 240(2):205-13. doi: 10.1097/01. sla.0000133083. 54934.ae.

14. Tiselius HG, Andersson A. Stone burden in an average Swedish population of stone formers requiring active Stone removal: How can the stone size be estimated in the clinical routine? Eur Urol 2003; 43(3):275-81. doi: 10.1016/s0302-2838(03)00006-x.

15. de la Rosette J, Assimos D, Desai M, Gutierrez J, Lingeman J, Scarpa R, et al. Croes PCNL study group. The clinical research office of the endourological society percutaneous nephrolithotomy global study: Indications, complications, and outcomes in 5803 patients. J Endourol 2011; 25(1):11-7. doi: 10.1089/end.2010.0424.

16. Song $Y$, Jin $W$, Hua S, Fei $X$. Middle calyx access is beter for single renal pelvic stone in ultrasound-guided percutaneous nephrolithotomy. Urolithiasis 2016; 44(5):459-63. doi: 10.1007/s00240-016-0866-9.

17. Tefekli A, Esen T, Olbert PJ, Tolley D, Nadler RB, Sun YH, et al. Croes PCNL study group. Isolated upper pole access in percutaneous nephrolithotomy: A large-scale analysis from the croes percutaneous nephrolithotomy global study. J Urol 2013; 189(2):568-73. doi: 10.1016/j.juro.2012.09.035.

18. Verma A, Tomar V, Yadav S. Complex multiple renal calculi: Stone distribution, pelvicalyceal anatomy and site of puncture as predictors of PCNL outcome. Springer Plus 2016; 5(1):1356. doi: 10.1186/s40064-016-3017-4.

19. Soucy F, Ko R, Duvdevani M, Nott L, Denstedt JD, Razvi H. Percutaneous nephrolithotomy for staghorn calculi: A single center's experience over 15 years. J Endourol 2009; 23(10):1669-73. doi: 10.1089/end.2009.1534.

20. Blum KA, Parkhomenko E, Thai J, Tran T, Gupta M. A contemporary lower pole approach for complete staghorn calculi: Outcomes and efficacy. World J Urol 2018; 36 (9):1461-7. doi: 10.1007/s00345-018-2284-9.

21. Binbay M, Akman T, Ozgor F, Yazici O, Sari E, Erbin A, et al. Does pelvicaliceal system anatomy affect success of percutaneous nephrolithotomy? Urology 2011;78(4):733-7. doi: 10.1016/j.urology.2011.03.058.

22. Caglayan V, Onen E, Avci S, Kilic M, Sambel M, Oner S. Percutaneous nephrolithotomy via a middle calyx access is effective in the treatment of lower pole kidney stones: A single-center study. Urol Int 2020; 104(9-10):741-5. doi: $10.1159 / 000505081$.

23. Falahatkar S, Kazemnezhad E, Moghaddam KG, Kazemzadeh M, Asadollahzade A, FarzanA, et al. Middle calyx access in complete supine percutaneous nephrolithotomy. Can Urol Assoc J 2013; 7(5-6):E306-10. doi: 10.5489/cuaj.11307. 
24. Michel MS, Trojan L, Rassweiler JJ. Complications in percutaneous nephrolithotomy. Eur Urol 2007; 51:899-906.

25. Soares RMO, Zhu A, Talati V, Nadler RB. Upper pole access for prone percutaneous nephrolithotomy: Advantage or risk? Urology 2019; 134:66-71. doi: 10.1016/j.urology. 2019.08.031. 